Abstracta Iranica Iranica

Revue bibliographique pour le domaine irano-aryen

Volume 42-43 | 2021

Comptes rendus des publications de 2019-2020

\title{
Małgorzata Sandowicz. Neo-Babylonian Dispute Documents in the British Museum
}

Louise Quillien

\section{(2) OpenEdition}

1 Journals

\section{Édition électronique}

URL : https://journals.openedition.org/abstractairanica/52780

DOI : 10.4000/abstractairanica.52780

ISSN : 1961-960X

Éditeur :

CNRS (UMR 7528 Mondes iraniens et indiens), Éditions de l'IFRI

\section{Référence électronique}

Louise Quillien, « Małgorzata Sandowicz. Neo-Babylonian Dispute Documents in the British Museum », Abstracta Iranica [En ligne], Volume 42-43 | 2021, document 41, mis en ligne le 30 juillet 2021, consulté le 14 décembre 2022. URL : http://journals.openedition.org/abstractairanica/52780 ; DOI : https:// doi.org/10.4000/abstractairanica.52780

Ce document a été généré automatiquement le 14 décembre 2022.

Tous droits réservés 


\title{
Małgorzata Sandowicz. Neo- Babylonian Dispute Documents in the British Museum
}

\author{
Louise Quillien
}

\section{RÉFÉRENCE}

Małgorzata Sandowicz. Neo-Babylonian Dispute Documents in the British Museum. Münster : Zaphon, 2019. 273 p., 56 pls. (dubsar 11).

1 L'ouvrage de Małgorzata Sandowicz comprend l'édition de 51 tablettes du British Museum concernant des litiges et leurs résolutions. Ces documents sont datés du VII au Ve siècle av. J.-C. et ils proviennent de différentes villes de Babylonie, y compris de localités peu documentées par ailleurs. Le chapitre 1 présente les affaires résolues par l'arbitrage et la négociation, sans avoir recours aux autorités judiciaires officielles (p. 1-18). Le chapitre 2 concerne les interrogatoires maš̀altu qui avaient lieu avant le jugement proprement dit, lors desquels les parties étaient convoquées et auditionnées en présence des autorités judiciaires et de témoins (p. 19-37). Le troisième chapitre est consacré aux comptes rendus de procès (p. 38-112) et le quatrième aux mémorandums de procédures judiciaires qui accompagnaient les dépositions et les déclarations ( $p$. 113-127). Le cinquième chapitre comprend les comptes rendus rédigés après le règlement des litiges (p. 128-156) et le sixième (p. 157-190) les textes qui n'entrent pas dans les catégories précédentes.

2 Parmi les textes édités, 19 sont datés des débuts de la période achéménide (CyrusDarius $\mathrm{I}^{\mathrm{er}}$ ) et apportent des informations sur l'exercice de la justice à cette période. Par exemple, une affaire impliquant des membres de l'entourage de Marduk-rēmanni a été portée devant Gūbaru, représentant de la Couronne achéménide en Babylonie, sous le règne de Cambyse (texte $n^{\circ} 22$ ). Selon Małgorzata Sandowicz, elle montre les connexions entre les élites babyloniennes et les représentants du pouvoir perse à cette 
période. Le texte $n^{\circ} 46$, probablement rédigé à Suse, concerne un partage d'héritage entre quatre frères de la famille Šangû-Šamaš (B), partage qui a probablement été réalisé pour pouvoir faire face aux obligations fiscales imposées par le pouvoir achéménide.

3 Les commentaires historiques et philologiques qui accompagnent chacun des textes édités s'attachent à établir le plus précisément possible la datation et la provenance des tablettes ainsi que leurs liens, notamment prosopographiques, avec les autres archives déjà connues. Małgorzata Sandowicz met en avant les nouvelles informations apportées par chacun de ces documents sur les procédures judiciaires et ses acteurs et elle montre que les officiers en charge de l'exercice de la justice diffèrent selon les villes concernées, selon la nature des affaires et leurs protagonistes. Les textes publiés apportent de nouvelles informations sur les lieux d'exercice de la justice, sur les personnes en charge de l'autorité judiciaire et sur les pratiques de l'écrit.

\section{AUTEURS}

\section{LOUISE QUILLIEN}

CNRS, UMR 7041, Arscan 